\title{
Influence of solar and geomagnetic storms on terrestrial photosynthesis
}

\author{
Lien Rodríguez-López ${ }^{1}$, Lisdelys González-Rodríguez ${ }^{2}$, Liuba Peñate-Alvariño ${ }^{3}$, Rolando \\ Cardenas $^{4, *}$, and Oscar Parra ${ }^{1}$ \\ ${ }^{1}$ Centre for Environmental Sciences EULA, University of Concepción, Concepción, Chile \\ ${ }^{2}$ Faculty of Engineering, University of Concepción, Concepción, Chile \\ ${ }^{3}$ Austral University of Chile, Valdivia, Chile \\ ${ }^{4}$ Planetary Science Laboratory, Universidad Central "Marta Abreu" de Las Villas, Santa Clara, Cuba
}

\begin{abstract}
It is reviewed the potential influence of solar and geomagnetic storms on terrestrial photosynthesis. Then it is presented a modification of a physical-mathematical model of photosynthesis published by some of us, which allows quantifying the influence of particulate ionizing radiation on this biological process. Some guidelines to obtain this new model from first principles are mentioned and it is applied to some case studies including atmospheric and geomagnetic perturbation due to solar storms.
\end{abstract}

\section{Introduction}

In the long course on Earth's biological evolution, several astrophysical phenomena might have delivered important doses of high energy muons on the planet's surface [1]. Neutron star mergers and core collapse supernovae are two examples.

High energy cosmic ray jets coming from nearby neutron star mergers, or due to their accretion induced collapse, can hit the atmosphere and produce lethal fluxes of atmospheric muons at ground level, underground and underwater, deplete the ozone layer, and radioactivate the environment.

These phenomena could have caused some of the massive life extinctions on planet Earth in the past $570 \mathrm{Myr}$. On another hand, biological mutations due to such ionizing radiations could have enhanced the fast appearance of new species after these mass extinctions.

Several studies acknowledge the high penetration power of high energy muons, quoting that they can travel through hundreds of meters in the ocean water column. However, the investigation of biological damage of muons on ocean phytoplankton is to be done. Thus, in this paper we present the damage on phytoplankton photosynthesis that a flux of high energy muons would do. Very illustrative are the scenarios of Cosmic Rays Bursts proposed in [2]. In this paper we focus in a less energetic but more frequent situation: solar storms. Due to the fact that they follow a cycle of approximately 22 years (11 years with a

*Corresponding author: rcardenas@uclv.edu.cu 
given polarity of the Sun's magnetic field, and the remaining 11 with the reverse polarity), several researchers have suggested consequent cyclical biological effects on Earth, mediated by several derived mechanisms: geomagnetic storms, perturbations of atmospheric chemistry, etc. This is the basis of a science that in Eastern Europe is usually called Heliobiology.

\section{Materials and Methods}

To quantify the action of solar storms we used a modification proposed by some of us of the so called $E$ model of photosynthesis to include particulate ionizing radiation [3]:

$$
P / P_{\mathrm{S}}(z)=\left[1-\mathrm{e}_{\mathrm{PAR}}^{-E_{\mathrm{P}}}(z) / E_{S}\right] /\left[f_{\mathrm{ir}}(z)+E_{\mathrm{UV}}^{*}(z)\right],
$$

where $P$ is the photosynthesis rate at depth $z, P_{S}$ is the maximum possible photosynthesis rate, $E_{\mathrm{PAR}}(z)$ is the irradiance of photosynthetically active radiation (PAR) at depth $z, E_{\mathrm{S}}$ is a parameter accounting how efficiently the species uses $\operatorname{PAR}, E^{*}{ }_{\mathrm{UV}}(z)$ is the irradiance of ultraviolet radiation (UV), convolved with a biological action spectrum measuring how much each UV wavelength inhibits photosynthesis (the reason for the asterisk), and $f_{\text {ir }}(z)$ is the function introduced by some of us in [3] to represent the influence of particulate ionising radiation. We considered independence between the effects of UV and muons, and used a biological action spectrum typical of temperate phytoplankton [4].

The irradiances of PAR and UV at sea level were calculated with the radiative transfer code Tropospheric Ultraviolet and Visible, developed at the National Centre for Atmospheric Research of USA, and free for download (https://www2.acom.ucar.edu/modeling/tropospheric-ultraviolet-and-visible-tuv-radiationmodel). It was assumed a solar zenital angle of 45 degrees (moderate radiational regime, typical of temperate regions), an ozone column of 300 Dobson units, an ocean albedo of 0,065 ; a cloud layer between 4 and $5 \mathrm{~km}$ above sea level with an optical depth of 0,00 ; and aerosols with an optical depth of 0,235 and a single scattering albedo of 0,990 . The radiation transfer model in the atmosphere was pseudo-spherical with two streams. The radiation transfer model in the ocean included the Lambert-Beer's law of Optics:

$$
E(\lambda, z)=E\left(\lambda, 0^{-}\right) \mathrm{e}^{-K(\lambda) \cdot z}
$$

where $E(\lambda, z)$ are the spectral irradiances at depth $z, E\left(\lambda, 0^{-}\right)$are the spectral irradiances just below ocean surface, and $K(\lambda)$ are the (wavelength-dependent) attenuation coefficients, which were taken from Jerlov's reference tables [5] and further interpolated according to [6]. In order to get a wide range of potential responses, we used ocean optical types I and III, which are the clearest and darkest in Jerlov's classification [5]. For the same reason, calculations were also made for coastal waters $\mathrm{C} 1$ and $\mathrm{C} 9$ of above mentioned classification. To complete this preliminary study, we included some freshwater ecosystems. These vary tremendously with respect to their optical quality, so we just selected two oligotrophic lakes of South-Central Chile (Riñihue and Laja), as some data concerning their attenuation coefficients for PAR and UV were available.

It was assumed that solar storms can increase at ocean surface both the muon flux and their average energy up to $10 \%$ respect to ordinary conditions. However, these increments were first treated separately, in order to weigh their relative importance, and then were considered together. The penetration of muons in the ocean was modeled through:

$$
I(z)=I_{0} \mathrm{e}^{-(\rho /) z},
$$


where $I_{0}$ and $I(z)$ are the particle fluxes $\left(\mathrm{m}^{-2}\right)$ at ocean surface and at depth $z, \rho$ is the density of water, and $l$ is a parameter measuring the penetrating efficiency of the particles of ionizing radiation (the bigger $l$, the more penetrating the particle). In this first modelling, it was not considered the disintegration of muons in their way down the water column, and it was assumed that the penetrating power depends linearly with their average energy $\langle E>$ :

$$
l=n<E>
$$

The average energy $<E_{S S}>$ of muons from solar storms can be written:

$$
<E_{\mathrm{SS}}>=m<E>
$$

where $m$ is a proportionality constant. Thus the penetrating power $l_{S S}$ of "solar" muons can e stated as:ujnu

$$
l_{S S}=n<E_{\mathrm{SS}}>=n m<E>=m l
$$

Following an ansatz formally analogous to the one used in [7, 3], we propose as the function of ionizing radiation:

$$
f_{\text {ir }}(z)=I_{\mathrm{SS}}(z) / I(z)=I_{0, \mathrm{SS}} \exp \left[-\left(\rho / l_{\mathrm{SS}}\right) z\right] / I_{0} \exp [[-(\rho / l) z],
$$

where the subscript ss means the scenario of the solar storm. Applying equation (6) to (7), after some algebra we get:

$$
f_{\text {ir }}(z)=\left(I_{0, \mathrm{SS}} / I_{0}\right) \exp \{-[(\mathrm{m}-1) / \mathrm{m}](\rho / l) z\}
$$

For our calculations we used $l=10^{4} \mathrm{~kg} / \mathrm{m}^{2}$, a typical value for muons from ordinary cosmic rays. We used three particular cases of equation (8). If there is only an increase in muon flux and average energy remains constant, it means $m=1$ in eq. (5), which implies the following form for the function of ionising radiation:

$$
f_{\text {ir }}(z)=I_{0, \mathrm{SS}} / I_{0}
$$

Assuming a $10 \%$ of increase of the muon flux means $f_{\text {ir }}(z)=1,1$. On another hand, if muon flux is constant and average energy increases in $10 \%$, this means $\mathrm{m}=1,1$ in equation (5), so equation (8) results:

$$
f_{\text {ir }}(z)=\exp [-0,09(\rho / 1) z]
$$

The third case is an increase of $10 \%$ in both variables, implying:

$$
f_{\text {ir }}(z)=1,1 \exp [-0,09(\rho / 1) z]
$$

\section{Results and Discussion}

Photosynthesis rates were calculated using the equations of the former section for three above mentioned potential radiational situations: 
a) the solar storm increments muon flux at sea level up to a $10 \%$,

b) the solar storm increments average muon energy at sea level up to a $10 \%$ and,

c) the solar storm increments both muon flux and average muon energy at sea level up to a $10 \%$.

For the sake of compactness we only show the plots for the third situation (Figure 1 to Figure 6), but summarize results in Table I.

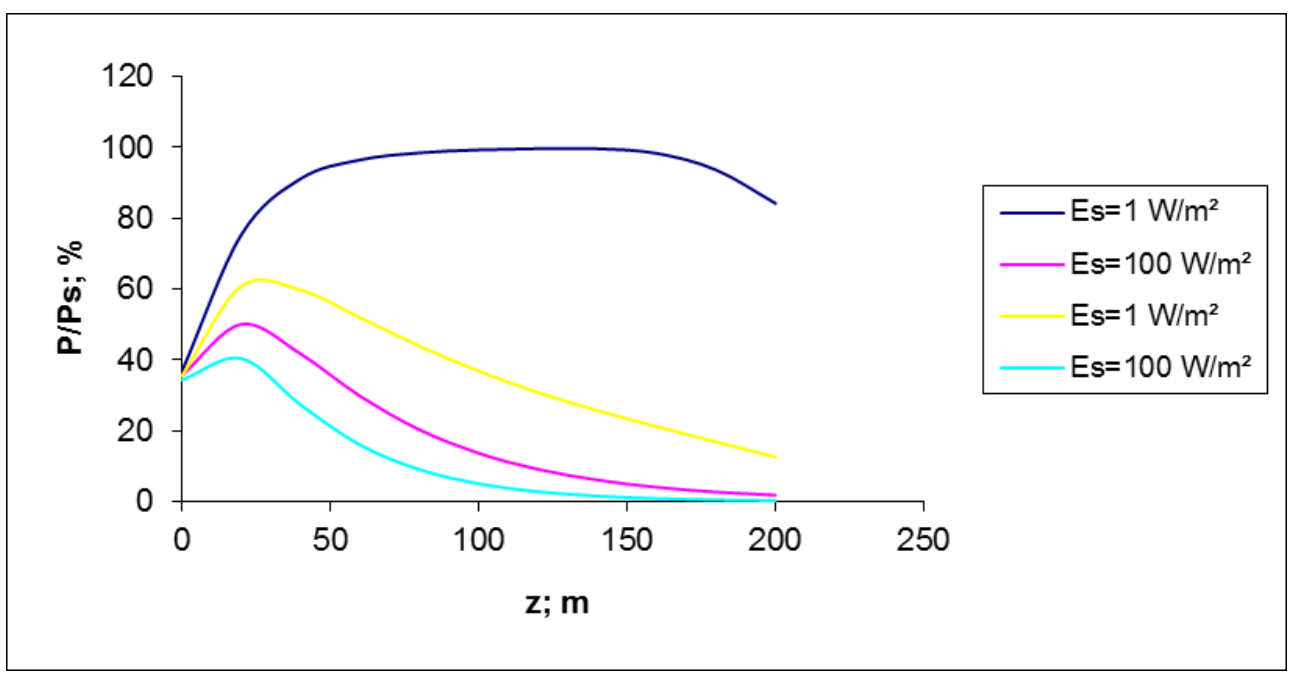

Fig. 1. Photosynthesis rates vs. depth for ocean water type I. Dark-blue and pink lines: usual radiational scenario. Yellow and blue-green lines: solar storm scenario

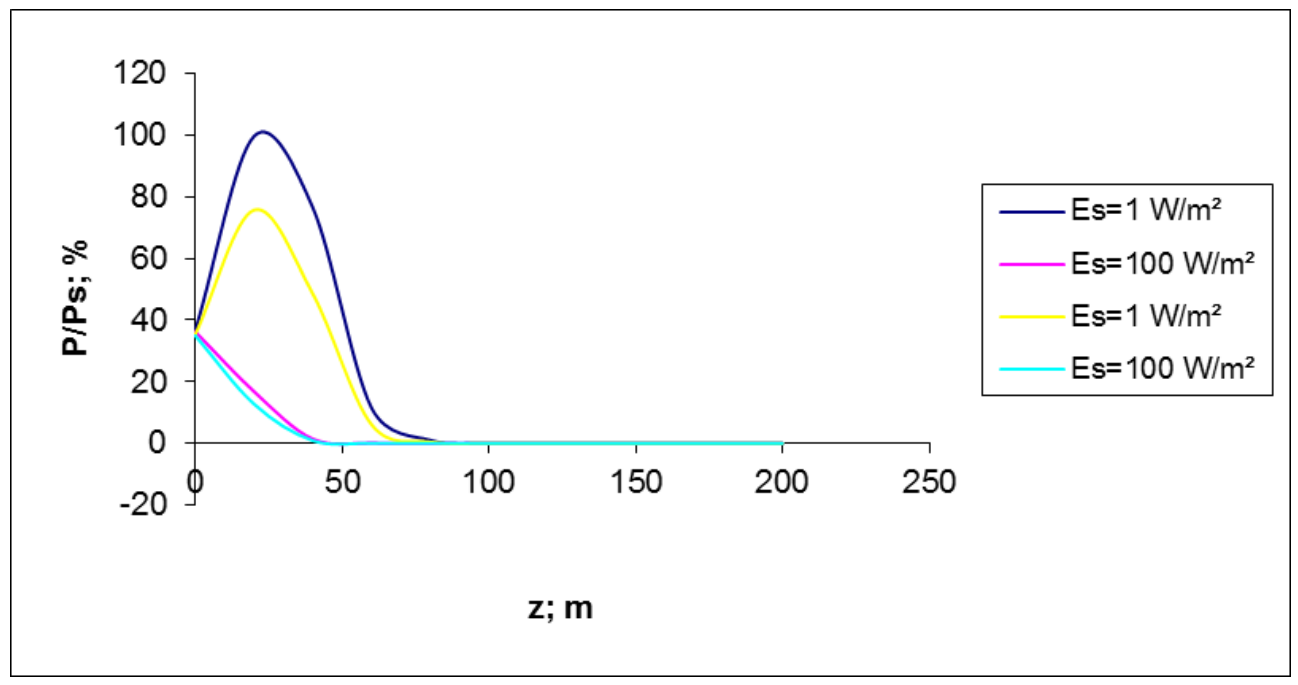

Fig. 2. Photosynthesis rates vs. depth for water type III. Dark-blue and pink lines: usual radiational scenario. Yellow and blue-green lines : solar storm scenario 


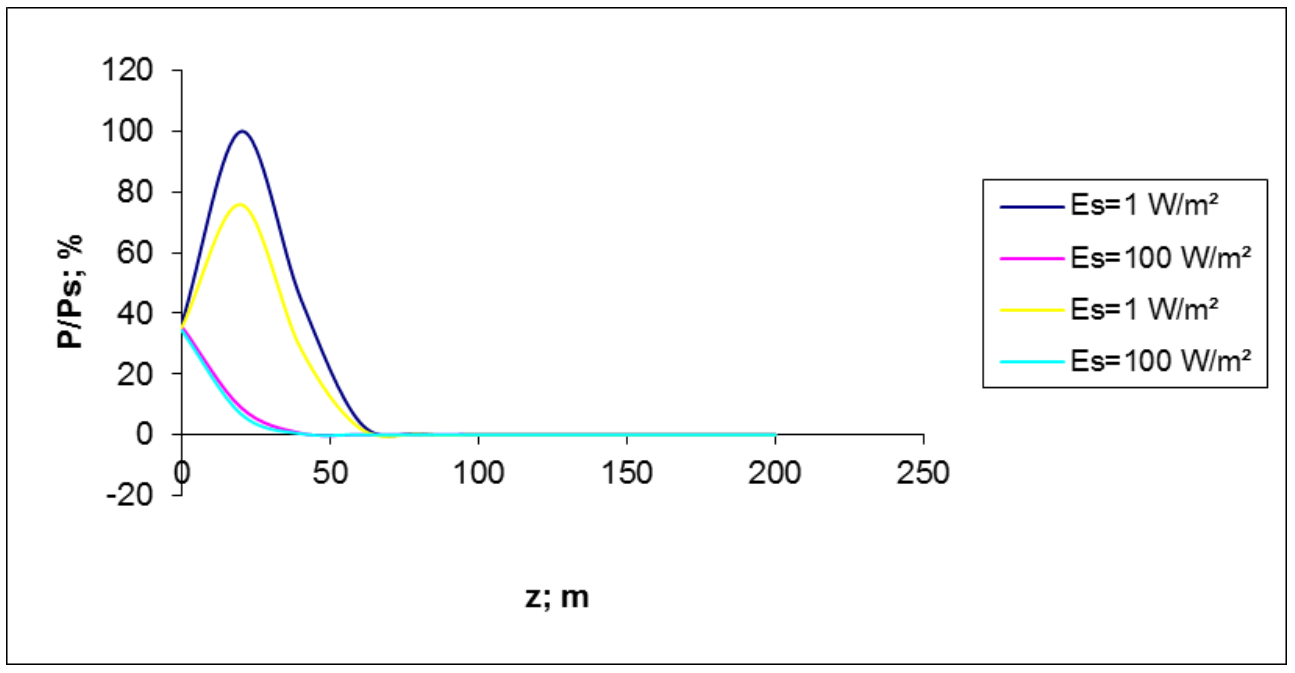

Fig. 3 Photosynthesis rates vs. depth for coastal water type 1. Dark-blue and pink lines: usual radiational scenario. Yellow and blue-green lines: solar storm scenario

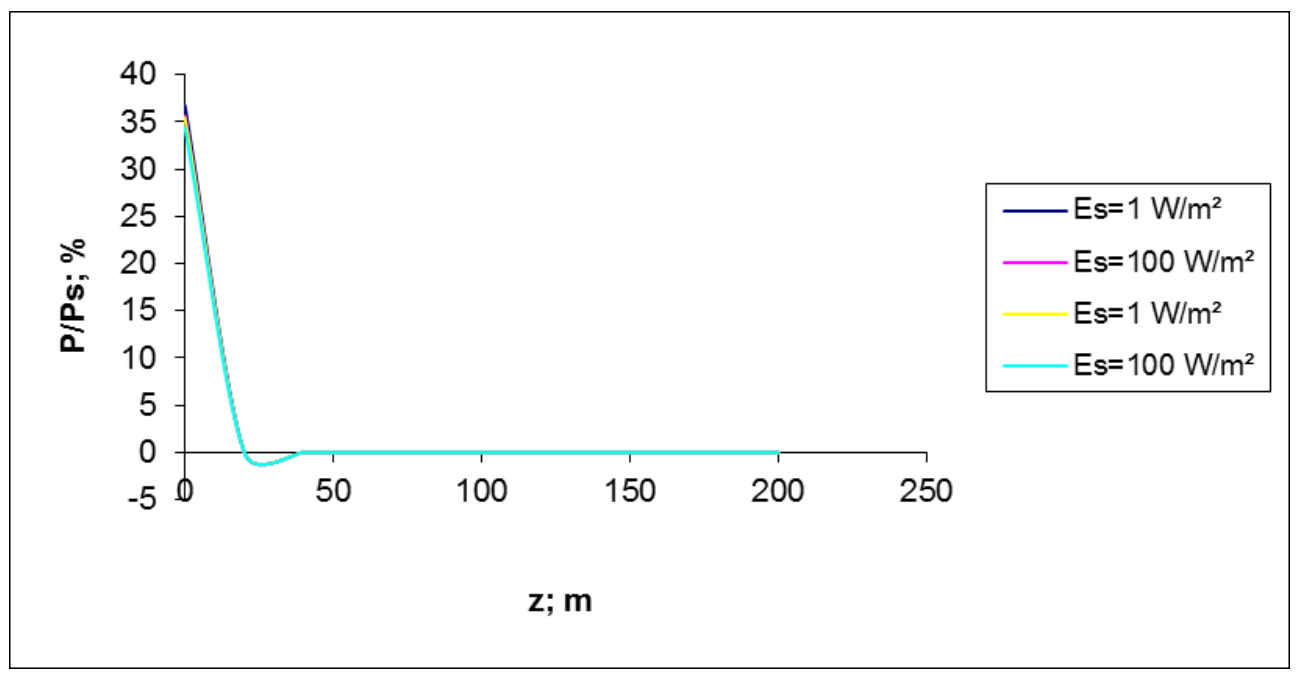

Fig. 4. Photosynthesis rates vs. depth for coastal water type 3. Dark-blue and pink lines: usual radiational scenario. Yellow and blue-green lines: solar storm scenario (apparent negative values due to interpolation procedure). 


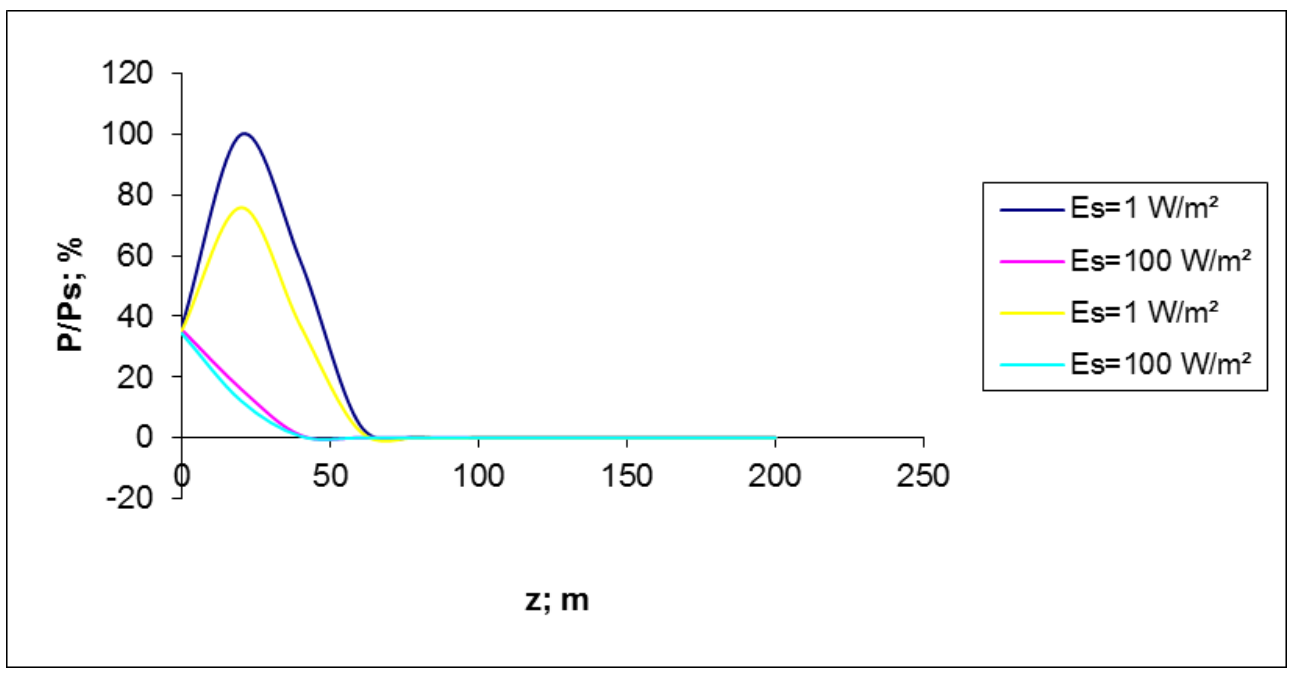

Fig. 5. Photosynthesis rates vs. depth for lake Riñihue. Dark-blue and pink lines: usual radiational scenario. Yellow and blue-green lines: solar storm scenario

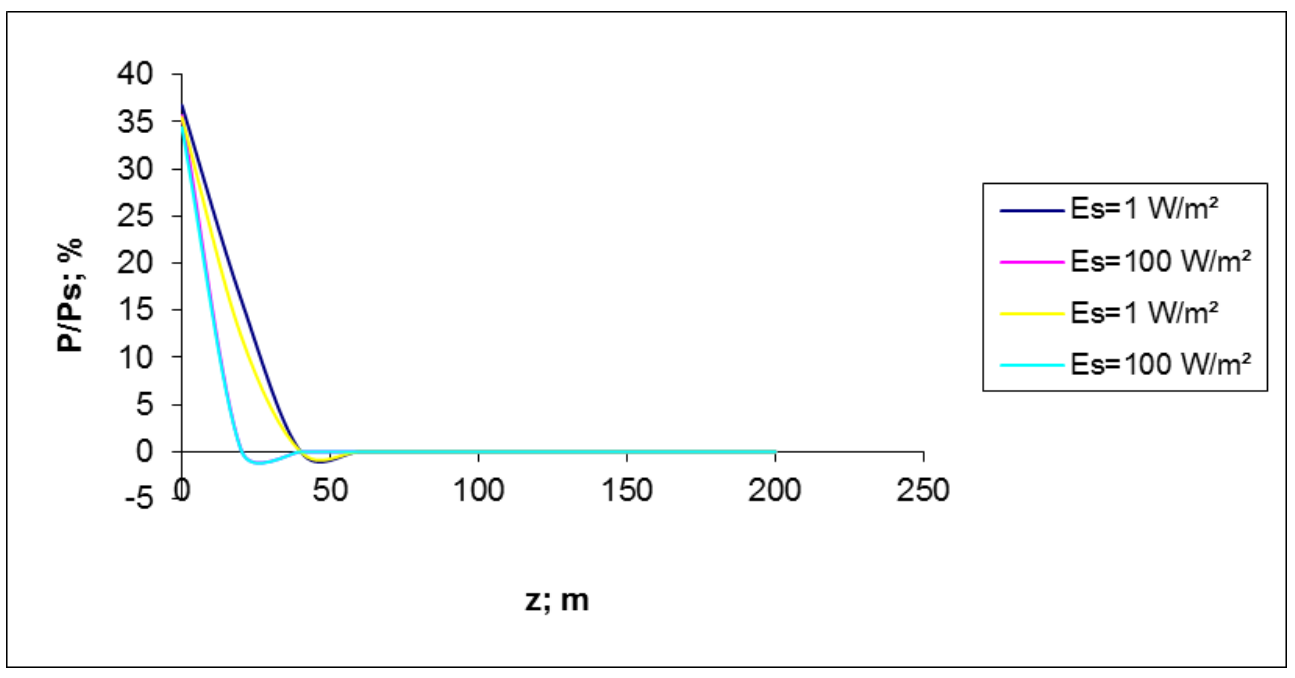

Fig. 6. Photosynthesis rates vs. depth for lake Laja. Dark-blue and pink lines: usual radiational scenario. Yellow and blue-green lines: solar storm scenario scenario (apparent negative values due to interpolation procedure).

In Table I we present relative photosynthesis reductions, considering depths beween 0 and 100 meters (because in most situations photosynthesis rates beneath 100 meters were negligible). It can be seen that in general the darker waters will less affected. This is to be expected, as usually dark waters are more protected against radiational phenomena. On another hand, in most cases the increase in average muon energy will have a much more inhibitory effect in photosynthesis than the increase of muon flux (assuming the increases are similar, $10 \%$ each). This can be explained because more energetic muons would have a 
greater penetrating power in the water column, making more effects in their journey through the photic zone.

Table I. Relative reduction (\%) of photosynthetic potential

\begin{tabular}{|c|c|c|c|}
\hline \multicolumn{4}{|c|}{ Effect of Increase of Muon Flux } \\
\hline \multicolumn{2}{|c|}{ Water Type I } & \multicolumn{2}{|c|}{ Water Type III } \\
\hline $\mathrm{E}_{\mathrm{S}}=1 \mathrm{~W} / \mathrm{m}^{2}$ & $\mathrm{E}_{\mathrm{S}}=100 \mathrm{~W} / \mathrm{m}^{2}$ & $\mathrm{E}_{\mathrm{S}}=1 \mathrm{~W} / \mathrm{m}^{2}$ & $\mathrm{E}_{\mathrm{S}}=100 \mathrm{~W} / \mathrm{m}^{2}$ \\
\hline 8,23 & 7,62 & 8,59 & 6,33 \\
\hline \multicolumn{2}{|c|}{ Water Type C1 } & \multicolumn{2}{|c|}{ Water Type C9 } \\
\hline $\mathrm{E}_{\mathrm{S}}=1 \mathrm{~W} / \mathrm{m}^{2}$ & $\mathrm{E}_{\mathrm{S}}=100 \mathrm{~W} / \mathrm{m}^{2}$ & $\mathrm{E}_{\mathrm{S}}=1 \mathrm{~W} / \mathrm{m}^{2}$ & $\mathrm{E}_{\mathrm{S}}=100 \mathrm{~W} / \mathrm{m}^{2}$ \\
\hline 8,48 & 5,49 & 3,56 & 3,55 \\
\hline \multicolumn{2}{|c|}{ Freshwater (Rinihue Lake, Summer) } & \multicolumn{2}{|c|}{ Freshwater (Laja Lake, Summer) } \\
\hline $\mathrm{E}_{\mathrm{S}}=1 \mathrm{~W} / \mathrm{m}^{2}$ & $\mathrm{E}_{\mathrm{S}}=100 \mathrm{~W} / \mathrm{m}^{2}$ & $\mathrm{E}_{\mathrm{S}}=1 \mathrm{~W} / \mathrm{m}^{2}$ & $\mathrm{E}_{\mathrm{S}}=100 \mathrm{~W} / \mathrm{m}^{2}$ \\
\hline 8,53 & 6,25 & 6,14 & 3,60 \\
\hline \multicolumn{4}{|c|}{ Effect of Increase of Average Muon Energy } \\
\hline \multicolumn{2}{|c|}{ Water Type I } & \multicolumn{2}{|c|}{ Water Type III } \\
\hline $\mathrm{E}_{\mathrm{S}}=1 \mathrm{~W} / \mathrm{m}^{2}$ & $\mathrm{E}_{\mathrm{S}}=100 \mathrm{~W} / \mathrm{m}^{2}$ & $\mathrm{E}_{\mathrm{S}}=1 \mathrm{~W} / \mathrm{m}^{2}$ & $\mathrm{E}_{\mathrm{S}}=100 \mathrm{~W} / \mathrm{m}^{2}$ \\
\hline 36,0 & 26,9 & 21,7 & 8,92 \\
\hline \multicolumn{2}{|c|}{ Water Type C1 } & \multicolumn{2}{|c|}{ Water Type C9 } \\
\hline$E_{S}=1 W / m^{2}$ & $\mathrm{E}_{\mathrm{S}}=100 \mathrm{~W} / \mathrm{m}^{2}$ & $\mathrm{E}_{\mathrm{S}}=1 \mathrm{~W} / \mathrm{m}^{2}$ & $\mathrm{E}_{\mathrm{S}}=100 \mathrm{~W} / \mathrm{m}^{2}$ \\
\hline 19,0 & 6,11 & 0,0536 & 0,000555 \\
\hline \multicolumn{2}{|c|}{ Freshwater (Rinihue Lake, Summer) } & \multicolumn{2}{|c|}{ Freshwater (Laja Lake, Summer) } \\
\hline $\mathrm{E}_{\mathrm{S}}=1 \mathrm{~W} / \mathrm{m}^{2}$ & $\mathrm{E}_{\mathrm{S}}=100 \mathrm{~W} / \mathrm{m}^{2}$ & $\mathrm{E}_{\mathrm{S}}=1 \mathrm{~W} / \mathrm{m}^{2}$ & $\mathrm{E}_{\mathrm{S}}=100 \mathrm{~W} / \mathrm{m}^{2}$ \\
\hline 19,9 & 8,41 & 7,70 & 0,161 \\
\hline \multicolumn{4}{|c|}{ Combined Effects } \\
\hline \multicolumn{2}{|c|}{ Water Type I } & \multicolumn{2}{|c|}{ Water Type III } \\
\hline $\mathrm{E}_{\mathrm{S}}=1 \mathrm{~W} / \mathrm{m}^{2}$ & $\mathrm{E}_{\mathrm{S}}=100 \mathrm{~W} / \mathrm{m}^{2}$ & $\mathrm{E}_{\mathrm{S}}=1 \mathrm{~W} / \mathrm{m}^{2}$ & $\mathrm{E}_{\mathrm{S}}=100 \mathrm{~W} / \mathrm{m}^{2}$ \\
\hline 41,2 & 32,4 & 28,3 & 14,4 \\
\hline \multicolumn{2}{|c|}{ Water Type C1 } & \multicolumn{2}{|c|}{ Water Type C9 } \\
\hline $\mathrm{E}_{\mathrm{S}}=1 \mathrm{~W} / \mathrm{m}^{2}$ & $\mathrm{E}_{\mathrm{S}}=100 \mathrm{~W} / \mathrm{m}^{2}$ & $\mathrm{E}_{\mathrm{S}}=1 \mathrm{~W} / \mathrm{m}^{2}$ & $\mathrm{E}_{\mathrm{S}}=100 \mathrm{~W} / \mathrm{m}^{2}$ \\
\hline 25,8 & 11,0 & 3,61 & 3,55 \\
\hline \multicolumn{2}{|c|}{ Freshwater (Rinihue Lake, Summer) } & \multicolumn{2}{|c|}{ Freshwater (Laja Lake, Summer) } \\
\hline $\mathrm{E}_{\mathrm{S}}=1 \mathrm{~W} / \mathrm{m}^{2}$ & $\mathrm{E}_{\mathrm{S}}=100 \mathrm{~W} / \mathrm{m}^{2}$ & $\mathrm{E}_{\mathrm{S}}=1 \mathrm{~W} / \mathrm{m}^{2}$ & $\mathrm{E}_{\mathrm{S}}=100 \mathrm{~W} / \mathrm{m}^{2}$ \\
\hline 26,6 & 13,9 & 13,1 & 3,75 \\
\hline
\end{tabular}

\section{Conclusions}

Using our modification of a model for photosynthesis to account for the influence of muons in this process, it was obtained for solar storms that in most cases the effect of the increase of average muon energy is greater than the effect of increase of muon flux, at least if the increase of both variables is similar. It was obtained that in general the darker waters would be less affected. In most cases the increase in average muon energy caused a greater inhibitory effect in photosynthesis than the increase of muon flux (assuming the increases are similar, $10 \%$ each). This could be explained because more energetic muons would have a greater penetrating power in the water column, making more effects in their journey through the photic zone. We consider this a rather pioneering study; we hope to improve 
these results in the near future using a more refined muon dosimetry and more accurate spectra for solar storms.

\section{References}

1. A.M. Melott, B.C. Thomas, Astrobiology, 11, 343-361 (2011)

2. A. Dar, A. Laor, N. Shaviv, Phys. Rev. Lett., 80, 5813-5816 (1998)

3. L. Rodriguez, R. Cardenas, O. Rodriguez, Int. J. Astrobiol., 12, 326-330 (2013)

4. P. Neale, personal comunication (2014)

5. N. Jerlov. Marine Optics. Elsevier, Amsterdam (1976)

6. L. Peñate, O. Martín, R. Cárdenas, S. Agustí, Astrophys. Space Sci., 330, 211-217 (2010)

7. D. Atri, A. Melott, Geophys Res Lett., 38, L19203 (2011)

\section{Acknowledgments}

We acknowledge colleagues Brian Thomas, Munish Kumar and Thomas Otto for useful comments on this work. 